\title{
Progress in adjuvant chemotherapy for breast cancer: an overview
}

\author{
Jesus Anampa*, Della Makower and Joseph A. Sparano
}

\begin{abstract}
Breast cancer is the most common cause of cancer and cancer death worldwide. Although most patients present with localized breast cancer and may be rendered disease-free with local therapy, distant recurrence is common and is the primary cause of death from the disease. Adjuvant systemic therapies are effective in reducing the risk of distant and local recurrence, including endocrine therapy, anti-HER2 therapy, and chemotherapy, even in patients at low risk of recurrence. The widespread use of adjuvant systemic therapy has contributed to reduced breast cancer mortality rates. Adjuvant cytotoxic chemotherapy regimens have evolved from single alkylating agents to polychemotherapy regimens incorporating anthracyclines and/or taxanes. This review summarizes key milestones in the evolution of adjuvant systemic therapy in general, and adjuvant chemotherapy in particular. Although adjuvant treatments are routinely guided by predictive factors for endocrine therapy (hormone receptor expression) and anti-HER2 therapy (HER2 overexpression), predicting benefit from chemotherapy has been more challenging. Randomized studies are now in progress utilizing multiparameter gene expression assays that may more accurately select patients most likely to benefit from adjuvant chemotherapy.
\end{abstract}

Keywords: Adjuvant chemotherapy, Anthracyclines, Breast cancer, Chemotherapy, Early breast cancer, Taxanes

\section{Background}

Breast cancer is the most frequently diagnosed cancer and the leading cause of cancer death among women, accounting for $25 \%$ of the total cancer cases (1.68 million) and $15 \%$ of the cancer deaths $(520,000)$ worldwide $[1,2]$. In the United States, it is estimated that there will be 231,840 new cases of invasive breast cancer and 40,290 deaths from the disease in 2015, and that one in eight women will develop breast cancer during their lifetime [3]. The disease is localized to the breast at presentation in $61 \%$ of cases, regionally advanced in $32 \%$, and metastatic in $7 \%$ [4]. When localized or regionally advanced, the disease is potentially curable with local and systemic therapy. Adjuvant systemic therapies reduce the risk of distant recurrence, presumably by treating micro-metastatic disease that may not be clinically evident at the time of local therapy. Prognostic factors for distant recurrence irrespective of treatment include classical clinicopathologic features such as tumor size, tumor grade, and number of axillary lymph nodes with metastasis. Predictive factors that identify

\footnotetext{
* Correspondence: janampa@montefiore.org

Department of Oncology, Montefiore Medical Center, Albert Einstein College of Medicine, Albert Einstein Cancer Center, Bronx, NY 10461, USA
}

benefit from specific therapies include expression of the estrogen receptor (ER) and progesterone receptor (PR), which identify patients who benefit from adjuvant endocrine therapy [5], and overexpression of human epidermal growth factor receptor 2 (HER2) protein (or HER2 gene amplification) [6], which identifies patients who benefit from adjuvant HER2-directed therapy. Multiparameter gene expression assays may also provide both prognostic information and prediction of benefit from adjuvant chemotherapy in patients with ER-positive disease [7, 8].

\section{An abbreviated history of adjuvant systemic therapy}

The initial approach to therapy for breast cancer was based on the premise that the disease metastasized via locoregional spread in an orderly fashion, and thus could be cured with aggressive surgery. The radical mastectomy was thus the standard surgical procedure for breast cancer in the early $20^{\text {th }}$ century [9]. Randomized trials subsequently showed no benefit from radical mastectomy compared with less aggressive surgical procedures, and demonstrated that distant recurrence remained a major clinical problem irrespective of the primary surgical therapy $[10,11]$. 
As the approach to local therapy evolved from more aggressive to less aggressive, the types of adjuvant systemic therapies and their indications expanded. A series of seminal clinical trials demonstrated that adjuvant systemic chemotherapy, endocrine therapy, and anti-HER2 directed therapy substantially reduced the risk of recurrence and improved overall survival when added to local therapy. In addition to the milestones achieved by individual trials summarized in Box 1, the Early Breast Cancer Trialists' Collaborative Group (EBCTCG) has periodically reported meta-analyses of all clinical trials with available data that have added to our knowledge about the benefits of adjuvant systemic therapy [12-16]. Based upon the improvements in outcomes associated with systemic therapies described below, current adjuvant therapy options summarized in Table 1 are commonly tailored to four phenotypic subtypes that are defined in a practical manner by utilizing information on ER, PR, and HER2 expression. This practical phenotypic classification roughly corresponds to "intrinsic subtypes" identified by gene expression profiling [17], although the latter classification may provide more accurate prognostic and predictive information $[18,19]$.

The first randomized trial evaluating adjuvant chemotherapy in breast cancer was the National Surgical Adjuvant Breast and Bowel Project (NSABP) B-01 trial initiated in 1958, which reported in 1968 that an adjuvant alkylating agent (thiotepa) given after radical mastectomy significantly decreased recurrence rate in pre-menopausal women with four or more positive axillary lymph nodes [20]. A subsequent randomized study reported in 1975 showed benefit from another alkylating agent (L-phenylalinine mustard) [21]. Other reports from the Istituto Nazionale Tumori in Milan, Italy, showed that combination chemotherapy regimen called "CMF" including an alkylating agent (cyclophosphamide) and antimetabolites (methotrexate and 5-fluorouracil) significantly reduced the risk of recurrence [22], thus ushering in the modern age of adjuvant polychemotherapy regimens that are now commonly used in clinical practice. These trials were among the first to establish a role for adjuvant chemotherapy, initially in premenopausal women with axillary node-positive disease at highest risk for recurrence [22], with subsequent trials also showing benefit in lower risk post-menopausal women [23] and women with axillary node-negative disease [24-26]. In 2001, a National Institute of Health consensus panel in the US concluded: "Because adjuvant polychemotherapy improves survival, it should be recommended to the majority of women with localized breast cancer regardless of lymph node, menopausal, or hormone receptor status." [27] Although the widespread adoption of more effective systemic therapies contributed to declining breast cancer mortality rates in the US and globally $[1,28]$, it also resulted in many patients being unintentionally
Box 1. Milestones in the adjuvant therapy of breast cancer

Chemotherapy

- Alkylating agents (thiotepa, L-phenylalinine mustard) given after surgery decrease recurrence rates [20, 21]

- Adjuvant polychemotherapy "CMF" regimen substantially reduces risk of recurrence [22] and improves survival [12, 25]

- National Institute of Health consensus panel recommends that adjuvant polychemotherapy be recommended to the majority of women with localized breast cancer regardless of lymph node, menopausal, or hormone receptor status [27]

- Anthracyclines and taxanes integrated into adjuvant chemotherapy regimens produce additional survival gains [16]

- Multiparameter gene expression assays identify subsets of patients with ER-positive disease who derive greatest benefit from adjuvant chemotherapy $[29,30]$ and are incorporated into evidence-based guidelines [31]

Endocrine therapy

- Adjuvant tamoxifen reduces recurrence [32] and improve survival $[12,33]$

- Five years of adjuvant tamoxifen therapy more effective than shorter durations [13]

- The proportional benefits of endocrine therapy are similar irrespective of nodal metastasis and that the benefits are seen only in patients with ER-positive tumors [15]

- Aromatase inhibitors are more effective than tamoxifen in postmenopausal women [34, 35]

- Extended adjuvant therapy for up to 10 years more effective than 5 years of therapy, including sequential tamoxifen followed by aromatase inhibitor [36], or tamoxifen for up to 10 years [37]

- Ovarian suppression plus an aromatase inhibitor was shown to be more effective than tamoxifen in premenopausal women at high risk for recurrence $[38,39]$

Anti-HER2 therapy

- Adjuvant trastuzumab reduces the risk of recurrence when added to adjuvant chemotherapy, given either concurrently or sequentially, in patients with HER2 overexpressing nodepositive or high-risk node-negative breast cancer [43]

- One year of trastuzumab was more effective than 6 months [46], 2 years of therapy was no more effective than 1 year [47]

- Addition of the HER2 tyrosine kinase inhibitor did not improve outcomes when added to trastuzumab [48] 
Table 1 Systemic adjuvant therapy options for operable breast cancer

\begin{tabular}{|c|c|c|c|c|c|}
\hline \multicolumn{3}{|c|}{ Breast cancer subtype/classification } & \multicolumn{3}{|c|}{ Adjuvant systemic therapy } \\
\hline Phenotypic subtype & & Intrinsic subtype & Endocrine therapy & Anti-HER2 therapy & Chemotherapy \\
\hline Hormone receptors & HER2 overexpression & & & & \\
\hline+ & - & Luminal $A$ or $B$ & Yes & No & Yes (if high risk) \\
\hline+ & + & Luminal B or HER2 enriched & Yes & Yes & Yes \\
\hline- & - & Basal & No & No & Yes \\
\hline- & + & HER2 enriched & No & Yes & Yes \\
\hline
\end{tabular}

"overtreated" with chemotherapy who might otherwise may been cured without it. Several multiparameter gene expression assays have recently been shown to provide prognostic information in patients with ERpositive breast cancer $[7,8]$ and also identify which patients derive greatest benefit from adjuvant chemotherapy $[29,30]$. Some of these assays are endorsed by evidence-based guidelines for making clinical decisions regarding the use of adjuvant chemotherapy in specific settings [31].

Approximately $75 \%$ of all breast cancers express hormone receptors [5]. Endocrine therapy reduces the risk of recurrence in hormone receptor-expressing disease, whether used alone or in addition to chemotherapy. In 1982, adjuvant tamoxifen given for 2 years was shown to reduce the risk of recurrence [32] and improve survival [33]. Subsequent studies and a meta-analyses of these studies confirmed a survival benefit [12], and also showed that 5 years of therapy was more effective than shorter durations, the proportional benefits were similar irrespective of nodal metastasis, and that the benefits were seen only in patients with ER-positive tumors [13, 15]. Aromatase inhibitors were subsequently shown to be more effective than tamoxifen in postmenopausal women [34, 35]. In addition, extended adjuvant therapy for up to 10 years was shown to be more effective than 5 years of therapy, including sequential tamoxifen followed by an aromatase inhibitor [36], or tamoxifen for up to 10 years [37]. Finally, in premenopausal women at high risk for recurrence, ovarian suppression plus an aromatase inhibitor was shown to be more effective than tamoxifen [38, 39].

Approximately $25 \%$ of all breast cancers overexpress the HER2 oncogene [6]. In 2005, several randomized trials demonstrated that addition of the anti-HER2 antibody trastuzumab to adjuvant chemotherapy, either concurrently or sequentially, substantially decreased the risk of recurrence in patients with HER2 overexpressing node-positive or high-risk node-negative breast cancer [40-43]. Addition of trastuzumab to sequential anthracycline/cyclophosphamide-taxane was associated with about a $3 \%$ risk of cardiac toxicity [40-42], while the combination of trastuzumab with non-anthracycline regimens (e.g. carboplatin/docetaxel) was associated with lower rates of cardiac toxicity [43]. Non-randomized single arm studies have also shown excellent outcomes in patients with lower risk node-negative disease not included in other studies who would have been expected to have higher recurrence rates without adjuvant trastuzumab [44, 45]. Subsequent studies demonstrated that 1 year of trastuzumab was more effective than 6 months [46], but 2 years of therapy was no more effective than 1 year [47]. The addition of the HER2 tyrosine kinase inhibitor lapatinib did not improve outcomes when added to trastuzumab [48].

\section{Adjuvant chemotherapy: first, second, and third generation regimens}

Adjuvant! is a web-based decision aid commonly used in clinical practice that allows clinicians and patients to better understand the potential benefits of adjuvant therapy, especially chemotherapy [49]. Estimates provided by Adjuvant! have been shown to correlate closely with actual clinical outcomes in population- and hospital-based cohorts $[50,51]$. Adjuvant! classifies adjuvant chemotherapy regimens as first, second, and third-generation, as exemplified in Table 2. A modification of this classification will be used here to categorize the numerous chemotherapy regimens discussed in this review, and to describe the clinical trials summarized in Table 3 . The regimens used in these studies generally included anthracyclines (doxorubicin, epirubicin) and/or taxanes (paclitaxel, docetaxel), which are the two most active classes of cytotoxic agents for both early and advanced stage breast cancer.

\section{Anthracyclines}

Anthracyclines, derivatives of the antibiotic rhodomycin B, were initially isolated in the 1950 s from gram-positive Streptomyces present in an Indian soil sample [52]. Doxorubicin was isolated from Streptomyces peucetius [53], a mutant of the original Streptomyces strain found near the Adriatic sea, and was therefore named Adriamycin. Doxorubicin was found to be one of the most active single cytotoxic agents in metastatic breast cancer $[54,55]$, although congestive cardiomyopathy emerged as a toxicity that required limiting the cumulative lifetime dose in order to minimize the risk of this toxicity [56]. Epirubicin, an epimer of doxorubicin differing in the orientation of the C4 hydroxyl group on the sugar, is a less cardiotoxic anthracycline than doxorubicin $[57,58]$. 
Table 2 Classification of adjuvant chemotherapy regimens

\begin{tabular}{lll}
\hline Generation* & Benefit & Regimens with substantial evidence base \\
\hline First & $35 \%$ reduction in breast cancer mortality compared with no adjuvant chemotherapy & CMFx6, ACx4, FEC50x6 \\
Second & $20 \%$ reduction in breast cancer mortality compared with first generation regimen & FEC100x6, CAFx6, FACx6 \\
& & ACx4-Tx4 (q3wks) \\
& DCx4, Ex4-CMFx4 \\
Third & $20 \%$ reduction in breast cancer mortality compared with second generation regimen & FECx4-Dx3, FECx4-weekly Tx8 \\
& & Concurrent DAC \\
& & Dose-dense ACx4-Tx4 \\
& & ACx4-weekly paclitaxel \\
& & ACx4-docetaxel (q 3 weeks)
\end{tabular}

*Adopted from Adjuvant online with modifications [50,51]

CMF, Cyclophosphamide, methotrexate, 5-flourouracil; AC, Doxorubicin, cyclophosphamide; FEC50, 5-flourouracil, epirubicin (50 mg/m²), cyclophosphamide; FEC100, 5-flourouracil, epirubicin $\left(100 \mathrm{mg} / \mathrm{m}^{2}\right)$, cyclophosphamide; DC, Docetaxel, cyclophosphamide; CAF, Cyclophosphamide, doxorubicin, 5-flourouracil;

FAC, 5-flouroracil, doxorubicin, cyclophosphamide; DAC, Docetaxel, doxorubicin, cyclophosphamide; T, paclitaxel; D, Docetaxel; E, Epirubicin

Table 3 Select phase III trials of first, second, and third generation trials

\begin{tabular}{|c|c|c|c|c|c|c|}
\hline Generation & Comparison (Reference) & Nodal status & $\begin{array}{l}\text { Number of } \\
\text { patients }\end{array}$ & $\begin{array}{l}\text { Median follow-up } \\
\text { (years) }\end{array}$ & $\begin{array}{l}\text { Hazard ratio for disease-free } \\
\text { survival }\end{array}$ & $\begin{array}{l}\text { Hazard ratio for overall } \\
\text { survival }\end{array}$ \\
\hline \multirow[t]{5}{*}{ First } & CMF vs no chemo $[22,71]$ & Positive & 386 & 28.5 & $0.71(P=0.005)$ & $0.79(P=0.04)$ \\
\hline & $\begin{array}{l}\text { CMF + Tam vs Tam (B20) } \\
{[26]}\end{array}$ & Negative & 2306 & 5 & $0.65(P=0.001)$ & $0.64(P=0.03)$ \\
\hline & AC vs CMF (B15) $[72,73]$ & Positive & 2194 & 3 & $P=0.5^{*}$ & $P=0.8^{*}$ \\
\hline & AC vs CMF (B23) [74] & Negative & 2008 & 5 & $P=0.9^{*}$ & $P=0.4^{*}$ \\
\hline & FEC50 + Tam vs Tam [76] & Positive & 457 & 9.4 & $0.46(P=0.0008)$ & $0.65(P=0.07)$ \\
\hline \multirow[t]{5}{*}{ Second } & FEC100 vs FEC50 [78] & Positive & 546 & 5.6 & $0.63(P=0.02)$ & $0.45(P=0.005)$ \\
\hline & $\begin{array}{l}\text { ACx4-Tx4 vs ACx4 (C9344) } \\
{[82]}\end{array}$ & Positive & 3121 & 5.8 & $0.83(P=0.002)$ & $0.82(P=0.006)$ \\
\hline & $\begin{array}{l}\text { ACx4-Tx4 vs ACx4 (B28) } \\
{[83]}\end{array}$ & Positive & 3060 & 5.4 & $0.83(P=0.006)$ & $0.93(P=0.46)$ \\
\hline & DCx4 vs ACx4 [85] & 0-3 Positive & 1016 & 7 & $0.74(P=0.033)$ & $0.69(P=0.032)$ \\
\hline & $\begin{array}{l}\text { Ex4-CMFx4 vs CMFx6/ } \\
\text { CMFx8 [84] }\end{array}$ & $\begin{array}{l}\text { Positive } \\
\text { Negative }\end{array}$ & 2391 & 4 & $0.69(P<0.001)$ & $0.67(P<0.001)$ \\
\hline \multirow[t]{10}{*}{ Third } & DAC vs FAC $[89,112]$ & Positive & 1491 & 10.3 & $0.80(P=0.004)$ & $0.74(P=0.002)$ \\
\hline & DAC vs FAC [91] & Negative & 1060 & 6.4 & $0.68(P=0.01)$ & $0.76(P=0.29)$ \\
\hline & FEC-D vs FEC $[92,93]$ & Positive & 1099 & 7.8 & $0.85(P=0.036)$ & $0.75(P=0.007)$ \\
\hline & FEC-weekly T vs FEC [95] & Positive & 1246 & 5.5 & $0.77(P=0.022)$ & $0.78(P=0.11)$ \\
\hline & FAC-weekly T vs FAC [113] & Negative & 1925 & 5.3 & $0.73(P=0.04)$ & $0.79(P=0.31)$ \\
\hline & Q3 vs q2wk ACT $[97,98]$ & Positive & 2005 & 5.8 & $0.80(P=0.01)$ & $0.85(P=0.04)$ \\
\hline & $\begin{array}{l}\text { AC-T vs AC-weekly T } \\
{[100,101]}\end{array}$ & Positive & 4954 & 12.1 & $0.84(P=0.011)$ & $0.87(P=0.09)$ \\
\hline & $A C-T$ vs $A C-D$ & & & & $0.79(P=0.001$ & $0.86(P=0.054)$ \\
\hline & AC-D vs DAC [103] & Positive & 5351 & 6.1 & $0.83(P=0.01)$ & $0.86(P=0.09)$ \\
\hline & $A C-D$ vs $A D$ & & & & $0.80(P=0.001)$ & $0.83(P=0.03)$ \\
\hline
\end{tabular}

CMF, Cyclophosphamide, methotrexate, 5-flourouracil; AC, Doxorubicin, cyclophosphamide; FEC50, 5-flourouracil, epirubicin (50 mg/m²), cyclophosphamide; FEC100, 5-flourouracil, epirubicin $\left(100 \mathrm{mg} / \mathrm{m}^{2}\right)$, cyclophosphamide; DC, Docetaxel, cyclophosphamide; CAF, Cyclophosphamide, doxorubicin, 5-flourouracil; FAC, 5-flouroracil, doxorubicin, cyclophosphamide; DAC, Docetaxel, doxorubicin, cyclophosphamide; T, Paclitaxel; D, Docetaxel; E, Epirubicin

*Hazard ratios were not reported in the manuscript; however $P$ values did not reveal any statistical significance between study arms 


\section{Taxanes}

Paclitaxel was originally isolated from the bark of the Pacific yew tree taxus brevifolia, and its antitumor activity was initially described in 1971 [59]. Paclitaxel binds to microtubules and induces their stabilization by inhibiting their depolymerization, thereby leading to mitotic arrest $[60,61]$ and chromosome missegregation on abnormal multipolar spindles [62, 63]. Despite its unique mechanism of action, paclitaxel's initial development was slow due to its scarcity and poor solubility. A formulation of paclitaxel solubilized in Cremophor EL was eventually developed but was associated with hypersensitivity reactions to the Cremophor EL vehicle [64], requiring premedication with corticosteroids and histamine blockers, which nearly thwarted paclitaxel's clinical development. In 1994, Cremophor-ELpaclitaxel was approved by the United States Food and Drug Administration (FDA) for treatment of metastatic breast cancer in patients who had progressed after anthracycline-based combination chemotherapy or who relapsed less than 6 months after adjuvant therapy [64]. In order to address the initial scarcity of paclitaxel, docetaxel, a semi-synthetic agent derived from the needles of the European yew tree taxus baccata, was developed [65]. Docetaxel has a similar mechanism of action to paclitaxel, but is a more potent microtubule inhibitor in vitro [65]. Docetaxel is also slightly more water-soluble than paclitaxel, and is dissolved in polysorbate-80. Despite the different solvent, premedication is also required to reduce the risk of acute hypersensitivity reactions and cumulative fluid retention associated with docetaxel infusions [66]. A direct comparison of docetaxel with paclitaxel in metastatic breast cancer showed greater efficacy for docetaxel but more toxicity [67], whereas a direct comparison of paclitaxel with doxorubicin as first line therapy showed comparable efficacy [68]. Both of these agents have been extensively tested in adjuvant trials based upon substantial single agent activity for each agent in metastatic breast cancer [69].

\section{First-generation chemotherapy regimen}

\section{Cyclophosphamide, methotrexate, and 5-fluorouracil (CMF)}

CMF was the first combination adjuvant chemotherapy regimen that was tested in a prospective clinical trial (Table 3). This trial, initiated in 1973 by the Istituto Nazionale Tumori in Milan, Italy, randomized node positive patients after radical mastectomy to 12 cycles of cyclophosphamide $\left(100 \mathrm{mg} / \mathrm{m}^{2}\right.$ orally on days $\left.1-14\right)$, methotrexate (40 $\mathrm{mg} / \mathrm{m}^{2} \mathrm{IV}$ on days 1 and 8 ), and 5fluorouracil $\left(600 \mathrm{mg} / \mathrm{m}^{2} \mathrm{IV}\right.$ on days 1 and 8 ) administered every 28 days versus no additional treatment [22]. The updated 342-month follow-up reported an improved disease-free survival (DFS; hazard ratio (HR), $0.71 ; P=$ 0.005 ) and overall survival (OS; HR, 0.79; $P=0.04$ ) for CMF compared with the control population. Another important finding was that relapse rate was no different when pre-menopausal women were compared to postmenopausal women. A subsequent study demonstrated that six cycles was as effective 12 cycles of adjuvant CMF [70], with results sustained after long-term follow-up [71]. A study conducted by the US Breast Cancer Intergroup found that six cycles of adjuvant CMF was also effective in reducing the risk of recurrence and improving survival in axillary node-negative disease [24, 25]. For patients with ER-positive, lymph node-negative disease at lower risk for recurrence, the NSABP B-20 trial found that the addition of CMF to tamoxifen improved 5-year DFS (HR, 0.65; $P=0.001)$ and OS (HR, 0.64; $P=0.03)$ [26]. The EBCTCG meta-analysis found that adjuvant $\mathrm{CMF}$ reduced the risk of recurrence by $30 \%$ at 10 years (HR, 0.70; $P<0.00001)$, which translated into an absolute gain of $10.2 \%$. The 10 -year overall mortality risk was reduced by $16 \%$ (HR, 0.84; $P<0.0004)$, which translated into an absolute gain of $4.7 \%$ at 10 years [16].

\section{Doxorubicin and cyclophosphamide (AC)}

One of the first adjuvant trials evaluating doxorubicin was NSABP B-11, which compared melphalan and 5fluorouracil with or without doxorubicin in 697 nontamoxifen responsive patients (defined as women 50-59 years with a tumor PR level by ligand binding assay of 0-9 fmol, and all patients $\leq 49$ years), and found an improved 5-year DFS (HR, 0.65; $P=0.007)$ and a trend to improved OS (HR, 0.74; $P=0.08$ ) for the doxorubicin arm [72]. In order to find a more intense and shorter chemotherapy regimen, the NSABP B-15 trial randomized 2,194 patients with node-positive disease to AC (doxorubicin $60 \mathrm{mg} / \mathrm{m}^{2}$ and cyclophosphamide $600 \mathrm{mg} / \mathrm{m}^{2}$ every 3 weeks for four cycles) given over 12 weeks versus conventional CMF for six cycles over 24 weeks (Table 3). The 3-year DFS rates $(62 \%$ vs $63 \% ; P=0.5)$ and OS rates ( $83 \%$ vs $82 \%$; $P=0.8$ ) were similar [73]. Subsequently, the NSABP B-23 trial showed no difference in outcomes in patients who were treated with $\mathrm{CMF}$ or $\mathrm{AC}$ in patients with nodenegative disease [74]. The EBCTCG meta-analysis found that comparison of CMF with AC yielded similar results for breast cancer mortality $(\mathrm{HR}, 0.98 ; P=0.67)[16]$. Other studies have found no advantage to administration of six compared to four cycles of AC, and superiority for AC compared with single agent paclitaxel given every 2 or 3 weeks [75].

\section{5-Flourouracil, epirubicin $\left(50 \mathrm{mg} / \mathrm{m}^{2}\right)$, and cyclophosphamide (FEC50)}

The French Adjuvant Study Group (FASG) compared epirubicin-based chemoendocrine therapy with tamoxifen alone in 457 postmenopausal women with ER-positive breast cancer and 1-3 positive nodes enrolled in two trials (FASG 2 and 7) [76]. The chemotherapy regimen was 
FEC50 (5-fluorouracil $500 \mathrm{mg} / \mathrm{m}^{2}$, epirubicin $50 \mathrm{mg} / \mathrm{m}^{2}$, cyclophosphamide $500 \mathrm{mg} / \mathrm{m}^{2}$ ), which was given every 3 weeks for six cycles concurrently with tamoxifen. The 9year DFS rates were $72 \%$ with tamoxifen and $84 \%$ with FEC50-tamoxifen (HR, 0.46; $P=0.0008)$. The 9-year OS rates were $78 \%$ and $86 \%$, respectively $(P=0.11)$. In the multivariate model, there was a trend in favor of chemoendocrine therapy for OS (HR, $0.65 ; P=0.07)$.

\section{Second generation chemotherapy regimens 5-Flourouracil, epirubicin $\left(100 \mathrm{mg} / \mathrm{m}^{2}\right)$, and cyclophosphamide (FEC100)}

After randomized trials demonstrated a dose-response relationship for epirubicin in metastatic breast cancer $[58,77]$, the FASG05 compared adjuvant fluorouracil $\left(500 \mathrm{mg} / \mathrm{m}^{2}\right)$ and cyclophosphamide $\left(500 \mathrm{mg} / \mathrm{m}^{2}\right)$ with epirubicin given at $50 \mathrm{mg} / \mathrm{m}^{2}$ (FEC50) or $100 \mathrm{mg} / \mathrm{m}^{2}$ (FEC100) every 21 days for six cycles (FEC50) [78]. After 5 years of follow-up, FEC100 showed improved DFS (HR, $0.63 ; P=0.02)$ and OS (HR, $0.45 ; P=0.005)$ compared to FEC50 [78] (Table 3).

\section{Cyclophosphamide, doxorubicin, and 5-fluorouracil (CAF or FAC)}

CAF is an acronym that is used to describe regimens in which cyclophosphamide is administered orally for 14 days and doxorubicin and 5-fluorouracil are given on days 1 and 8 every 28 days for six cycles, whereas FAC is an acronym used to describe a regimen in which all of these agents are given IV every 3 weeks for six cycles. The SWOG-8814/ INT-0100 trial randomized postmenopausal women with hormone-receptor positive, node-positive breast cancer to CAF plus tamoxifen versus tamoxifen alone. DFS was superior for CAF plus tamoxifen (HR, $0.76 ; P=0.002$ ), but OS was only marginally improved (HR, $0.83 ; P=0.057)$ [23]. The EBCTCG meta-analysis found that breast cancer mortality rates were reduced more with FAC for six cycles (HR, 0.64; $P<0.0001)$ than AC for four cycles $(\mathrm{HR}, 0.78$; $P=0.01$ ) or $\mathrm{CMF}$ for six cycles (risk ratio, $0.76 ; P<0.0001$ ) [16], and that FAC or FEC combinations were more effective in reducing breast cancer mortality compared to CMF (risk ratio, 0.78; $P=0.0004$ ) [16].

\section{Sequential doxorubicin/cyclophosphamide followed by paclitaxel (AC-T)}

Concurrent administration of paclitaxel and doxorubicin, two of the most active cytotoxic agents for metastatic breast cancer, was associated with substantial activity, but led to prohibitive cardiotoxicity due to a pharmacokinetic interaction resulting in greater doxorubicin exposure [79]. In addition, mathematical modeling predicted that sequential administration of cytotoxic agents at their optimal doses would result in more effective antitumor activity than their concurrent administration [80, 81]. Therefore, two phase 3 trials evaluated sequential administration of paclitaxel after anthracycline-containing therapy (Table 3). CALGB 9344 employed a $2 \times 2$ factorial design evaluating escalating doses of doxorubicin $\left(60,75\right.$, or $\left.90 \mathrm{mg} / \mathrm{m}^{2}\right)$ in combination with cyclophosphamide $\left(600 \mathrm{mg} / \mathrm{m}^{2}\right)$ every 21 days for four cycles, given alone, or followed sequentially by four cycles of paclitaxel ( $175 \mathrm{mg} / \mathrm{m}^{2}$ IV every 21 days) in 3,121 patients with node-positive breast cancer. After a median follow-up of 69 months, the addition of paclitaxel was associated with improved DFS (HR, 0.83; $P=0.0023)$ and OS (HR, 0.82; $P=0.006$ ). Escalation of doxorubicin dose had no impact on outcomes [82]. In the NSABP B-28 trial, after a median follow-up of 65 months, the sequential addition of four cycles of paclitaxel $\left(225 \mathrm{mg} / \mathrm{m}^{2}\right)$ to four cycles of $\mathrm{AC}$ in 3,060 patients with node-positive breast cancer improved DFS (HR, 0.83; $P=0.006)$ but not OS (HR, $0.93 ; P=0.46)$ [83]. Endocrine therapy with tamoxifen was given after chemotherapy in the C9344 trial in patients with ER-positive disease, whereas it was given concurrently with chemotherapy in the B28 trial for patients 50 years of age or older, and those younger than 50 with ER- and/or PR-positive tumors. Other studies have suggested greater benefit from adjuvant chemotherapy in postmenopausal women with ER-positive disease when tamoxifen is initiated sequentially following completion of chemotherapy [23]. The results of the C9344 study supported FDA approval of adjuvant paclitaxel in the US.

\section{Sequential epirubicin followed by CMF}

The National Epirubicin Adjuvant Trial (NEAT) and BR9601 trials evaluated the efficacy of epirubicin followed by CMF. The BR9601 trial used a modified CMF regimen (cyclophosphamide $750 \mathrm{mg} / \mathrm{m}^{2}$, methotrexate $50 \mathrm{mg} / \mathrm{m}^{2}$, and 5 -flouorouracil $600 \mathrm{mg} / \mathrm{m}^{2}$ on day 1 every 3 weeks) whereas the NEAT trial used classic CMF. Both trials compared four cycles of epirubicin $100 \mathrm{mg} / \mathrm{m}^{2}$ every 3 weeks followed by four cycles of CMF (epirubicin-CMF) versus CMF alone (six cycles in NEAT, eight cycles in BR9601). Combined analysis included 2,391 patients. After a median follow-up of 48 months, epirubicin-CMF group was associated with improved DFS (HR, 0.69; $P<0.001$ ) and OS (HR, 0.67; $P<0.001)$ compared to CMF alone [84].

\section{Docetaxel plus cyclophosphamide}

The US Oncology Research phase III trial evaluated 1,016 patients with operable breast cancer who were assigned to four 3-week cycles of AC (doxorubicin $60 \mathrm{mg} / \mathrm{m}^{2}$ and cyclophosphamide $600 \mathrm{mg} / \mathrm{m}^{2}$ ) or DC (docetaxel $75 \mathrm{mg} / \mathrm{m}^{2}$ and cyclophosphamide $600 \mathrm{mg} / \mathrm{m}^{2}$ ) [85] (Table 3). After a median follow-up of 84 months, DC was associated with significantly improved DFS (HR, $0.74 ; P=0.033)$ and $\mathrm{OS}(\mathrm{HR}, 0.69 ; P=0.032)$. 


\section{Third generation chemotherapy regimens}

\section{Docetaxel, doxorubicin, and cyclophosphamide (DAC)}

Unlike paclitaxel, docetaxel does not have a major pharmacokinetic interaction with doxorubicin, and does not increase doxorubicin-related cardiotoxicity when given concurrently [86-88]. Two studies compared a combination of docetaxel, doxorubicin, and cyclophosphamide (DAC) with FAC (Table 3). The Breast Cancer International Research Group 0001 trial compared six cycles DAC (docetaxel $75 \mathrm{mg} / \mathrm{m}^{2}$, doxorubicin $50 \mathrm{mg} / \mathrm{m}^{2}$, and cyclophosphamide $500 \mathrm{mg} / \mathrm{m}^{2}$ ) with FAC (5-fluorouracil $500 \mathrm{mg} / \mathrm{m}^{2}$, doxorubicin $50 \mathrm{mg} / \mathrm{m}^{2}$, and cyclophosphamide $500 \mathrm{mg} / \mathrm{m}^{2}$ ) every 3 weeks as adjuvant treatment for 1,491 women with operable node-positive breast cancer $[89,90]$. After a median follow-up of 124 months, there were improvements in DFS (HR, 0.80; $P=0.0043)$ and OS (HR, 0.74; $P=0.002$ ). The benefit in DFS was irrespective of nodal, hormone receptor, and HER2 status. The GEICAM 9805 trial compared six cycles of DAC with FAC in 1,060 patients with node-negative breast cancer [91]. After a median follow-up of 77 months, there was a significant improvement in DFS (HR, 0.68; $P=0.01)$ and a trend toward improved OS (HR, 0.76; $95 \% \mathrm{CI}, 0.45$ to 1.26; $P=0.29$ ) favoring DAC. In both trials, DAC was associated with considerably more toxicity, including febrile neutropenia.

\section{Sequential FEC-taxane therapy}

Although it was clear that results improved when taxanes were added sequentially following anthracyclines, it was unclear as to whether this improvement was specifically due to the sequential addition of a taxane, or due to more prolonged duration of adjuvant chemotherapy administration. Three trials described herein directly addressed this question by comparing an anthracycline-containing regimen and a sequential anthracycline-taxane regimen in which the treatment arms had a comparable duration (Table 3). The PACS01 trial evaluated six 3-week cycles of FEC (5-fluorouracil $500 \mathrm{mg} / \mathrm{m}^{2}$, epirubicin $100 \mathrm{mg} / \mathrm{m}^{2}$, and cyclophosphamide $500 \mathrm{mg} / \mathrm{m}^{2}$ ) with three cycles of FEC followed by docetaxel (100 $\mathrm{mg} / \mathrm{m}^{2}$ every 3 weeks) for three cycles in 1,999 patients with node-positive breast cancer [92]. After a median follow-up of 93 months, the sequential taxane arm was associated with improved DFS (HR, 0.85; $P=0.036)$ and OS (HR, 0.75; $P=0.007)$ [93]. The UK TACT study randomized 4,162 women with node-positive or high-risk node-negative breast cancer to four cycles of FEC followed by four cycles of docetaxel $\left(100 \mathrm{mg} / \mathrm{m}^{2}\right.$ every 3 weeks) versus a control regimen consisting of physician's choice of eight cycles of FEC (5-fluorouracil $600 \mathrm{mg} / \mathrm{m}^{2}$, epirubicin $60 \mathrm{mg} / \mathrm{m}^{2}$, and cyclophosphamide $600 \mathrm{mg} / \mathrm{m}^{2}$ ) or epirubicin for four cycles followed by four cycles of CMF. After a median follow-up of 62 months, there was no significant difference in outcome between the arms [94]. In the GEICAM 9906 trial, 1,246 patients with node-positive breast cancer patients were randomized to six cycles of FEC (5-fluorouracil $600 \mathrm{mg} / \mathrm{m}^{2}$, epirubicin $90 \mathrm{mg} / \mathrm{m}^{2}$, and cyclophosphamide $600 \mathrm{mg} / \mathrm{m}^{2}$ ) or four cycles of FEC followed by eight weekly doses paclitaxel (100 $\mathrm{mg} / \mathrm{m}^{2}$ per week). After a median of 66 months, the sequential paclitaxel arm was associated with a reduced risk of recurrence (HR, 0.77; $P=0.022)$ and trend toward a lower risk of death (HR, $0.78 ; P=0.110)$ [95].

The specific benefit of sequential addition of a taxane was also addressed in the 2012 EBCTCG meta-analysis [16]. In trials adding four separate cycles of a taxane to a fixed anthracycline-based control regimen and extending treatment duration, breast cancer mortality was reduced (HR, 0.86; $P=0.0005$ ). However, in trials with four such extra cycles of a taxane counterbalanced in controls by extra cycles of other cytotoxic drugs, roughly doubling non-taxane dosage, there was no significant difference in breast cancer mortality (HR, 0.94; $P=0.33)$. Although these results would suggest similar benefits for a 24-compared to a 12-week adjuvant cytotoxic regimen irrespective of which agents are used, the sequential approach may minimize the delayed effects of anthracyclines whose risk increases with greater cumulative dose.

\section{Dose dense sequential doxorubicin/cyclophosphamide- paclitaxel (AC-T)}

The concept of dose density has been also evaluated in some adjuvant therapies for breast cancer. Dose density refers to administering the same therapeutic regimen (without changing actually doses given) at more frequent intervals, with the goal of decreasing the time for cancer cells to recover in between chemotherapy cycles $[80,96]$. The C9741 assessed the impact of dose density (2 week vs 3 week) and treatment sequence (concurrent vs sequential) in patients with operable breast cancer by randomizing 2,005 patients to four different treatment arms using a $2 \times 2$ factorial design to: (1) concurrent AC-T (paclitaxel) versus sequential A-C-T and (2) every 3 weeks versus a dose-dense regimen every 2 weeks plus filgrastim [97] (Table 3). At 36-month follow-up, the dosedense regimen improved the primary end-point DFS (HR, $0.74 ; P=0.01)$ and $\mathrm{OS}(\mathrm{HR}, 0.69 ; P=0.013)$. There was no difference in either DFS or OS between the concurrent and sequential schedules [97]. Updated results after a median 6.5 years of follow-up continue to favor dose-dense chemotherapy in DFS (HR, 0.80; $P=0.01)$ and OS (HR, $0.85 ; P=0.04)$ [98]. The dose-dense schedule was associated with improved DFS (HR, 0.76; $P=0.01$ ) and OS (HR, $0.79 ; P=0.04)$ in ER-negative disease but not ER-positive disease.

A systemic review and meta-analysis identified 10 trials that met the inclusion criteria for evaluating the effect of 
dose-dense chemotherapy scheduling [99]. Three trials, enrolling 3,337 patients, compared dose-dense chemotherapy with a conventional chemotherapy schedule (similar agents). Patients who received dose-dense chemotherapy had improved OS (HR, 0.84; $P=0.03)$ and DFS (HR, 0.83; $P=0.005)$ compared with those who received the conventional schedule, although no benefit was observed in patients with hormone receptor-positive tumors. Seven trials, enrolling 8,652 patients, compared dose-dense chemotherapy with regimens that use standard intervals but with different agents and/or dosages in the treatment arms. Similar results were obtained for these trials with respect to OS (HR, 0.85; $P=0.01)$ and DFS (HR, 0.81; $P<0.001)$. The rate of non-hematological adverse events was higher in the dose-dense chemotherapy arms than in the conventional chemotherapy arms.

\section{Sequential AC-weekly paclitaxel or every 3 week docetaxel} The ECOG E1199 trial was designed to identify the optimal taxane and schedule. This trial enrolled 4,954 patients with stage II-III breast cancer who received standard AC followed sequentially by taxane therapy using a $2 \times 2$ factorial design. The study found no difference in the primary comparisons of taxane (paclitaxel vs docetaxel) and schedule (every 3 weeks vs weekly); other pre-specified analyses included a comparison of the standard every 3 week paclitaxel arm $\left(175 \mathrm{mg} / \mathrm{m}^{2}\right)$ for four cycles (P3 control arm) with weekly paclitaxel $\left(80 \mathrm{mg} / \mathrm{m}^{2}\right)$ for 12 weeks $(\mathrm{P} 1 \mathrm{arm})$, docetaxel $\left(100 \mathrm{mg} / \mathrm{m}^{2}\right)$ every 3 weeks for four cycles (D3 arm), or weekly docetaxel $\left(35 \mathrm{mg} / \mathrm{m}^{2}\right)$ for 12 weeks (D1 arm) [100]. After a median follow-up of 5.3 years, the P1 arm was associated with improved DFS (HR, $0.73 ; P=0.006)$ and OS (HR, 0.68; $P=0.01)$ compared with the P3 arm. Although improved DFS was also observed for the D3 arm (HR, 0.77; $P=0.02$ ) without a survival benefit, it was associated with substantially more toxicity than the P1 arm. In an updated analysis after a median follow-up of 12.1 years, DFS was significantly improved and OS marginally improved for both the P1 arm (HR, 0.84; $P=0.011$ and HR, 0.87; $P=0.09$, respectively) and D3 arm (HR, $0.79 ; P=0.001$ and HR, $0.86 ; P=0.054$, respectively). Although weekly paclitaxel improved DFS and OS (HR, 0.69; $P=0.010$ and HR, 0.69; $P=0.019$, respectively) in triple negative breast cancer, no experimental arm improved OS for hormone receptor-positive, HER2 non-overexpressing breast cancer [101]. Another trial found no difference in outcomes comparing weekly paclitaxel $\left(80 \mathrm{mg} / \mathrm{m}^{2}\right.$ for 12 doses $)$ with biweekly paclitaxel given at a higher dose $\left(175 \mathrm{mg} / \mathrm{m}^{2}\right.$ for six doses) given sequentially after $\mathrm{AC}$, although there was more toxicity with biweekly higher dose paclitaxel schedule [102].

\section{Sequential versus concurrent taxane administration}

The NSABP B30 trial addressed the question of whether docetaxel is best given concurrently with or sequentially following doxorubicin [103]. The study included 5,351 patients with node-positive breast cancer to receive four cycles of AC followed by four cycles of docetaxel (sequential AC-D), four cycles of doxorubicin and docetaxel (AD), or four cycles of doxorubicin, cyclophosphamide, and docetaxel (concurrent DAC). After a median follow-up of 73 months, DFS was improved in the sequential-AC-D arm compared with the $\mathrm{AD}(\mathrm{HR}, 0.80 ; P=0.001)$ and the concurrent DAC arm (HR, 0.83; $P=0.01)$, and OS was likewise improved in the sequential-ACD arm compared with the $\mathrm{AD}$ arm $(\mathrm{HR}, 0.83 ; P=0.03)$ and concurrent DAC arm (HR, 0.86; $P=0.09)$.

\section{Predicting benefit from chemotherapy}

In the EBCTC meta-analyses involving taxane-based or anthracycline-based regimens, proportional reductions in risk of recurrence associated with adjuvant chemotherapy were little affected by age, nodal status, tumor diameter or grade, ER expression, or tamoxifen use, and breast cancer mortality was reduced on average by one-third [16]. Several multiparameter gene expression assays have been shown to provide prognostic information in patients with ER-positive breast cancer [7, 8] and also identify which patients derive greatest benefit from adjuvant chemotherapy $[29,30]$. Currently available assays include the Oncotype DX (Genomic Health, Inc., Redwood City, CA), MammaPrint (Agendia, Inc. USA, Irvine, CA), Prosigna (Nanostring Technologies, Seattle, WA), and Breast Cancer Index $^{\text {SM }}$ (bioTheranostics, Inc., San Diego, CA). Some of these assays are endorsed by evidence-based guidelines for making clinical decisions regarding the use of adjuvant chemotherapy in specific settings [31]. Nevertheless, the assays may not inform treatment decisions in up to approximately $50 \%$ of those tested [104]. Randomized trials are in progress in order to determine whether chemotherapy may be safely spared in patients with tumors associated with low risk signatures who would otherwise have been advised to receive chemotherapy based on classic clinicopathologic features [105, 106]. For example, in the Trial Assigning Individualized Options for Treatment (TAILORx) (NCT00310180), patients with ER-positive, HER2-negative, axillary node negative disease who meet National Comprehensive Cancer Center Network guidelines for recommending adjuvant chemotherapy are assigned to endocrine therapy alone if the Oncotype DX Recurrence Score (RS) is very low $(<11)$ or chemoendocrine therapy if the RS is in the high or high-intermediate range $(>25)$, and are randomized to chemoendocrine therapy versus endocrine therapy if there is a mid-range RS of 11-25[105]. Likewise, in the clinical trial for treatment of endocrine responsive breast cancer 
(RxPONDER) (NCT01272037), patients with one to three positive axillary nodes are assigned to chemoendocrine therapy if the RS $>25$ and randomized to chemoendocrine therapy versus endocrine therapy if the RS is $<26$ (https:// clinicaltrials.gov/ct2/show/NCT01272037). The cut points used in these trials differ from the originally classification of low (RS $<18$ ), intermediate (RS18-30), and high (RS $>30)$ in order to minimize the potential for chemotherapy under-treatment [105].

\section{Tailoring the optimal regimen for individual patients}

Factors considered in selecting patients for adjuvant therapy include tumor-specific factors, such as tumor size, axillary node metastasis, and tumor biology (i.e. ER/PR and HER2 expression, multiparameter gene expression assays), and patient specific factors such as age, comorbidities, and patient preference. A risk classification and potential therapeutic options for each risk category is proposed in Table 4. Patients with T1a tumors $(1-5 \mathrm{~mm})$ and negative nodes are at very low-risk of recurrence and generally do not require systemic chemotherapy. Patients with intermediate or high-risk disease should receive chemotherapy, whereas those with low-risk disease may be considered for chemotherapy if younger ( $<50-60$ years). Patients with high-risk disease requiring chemotherapy are usually advised to receive an anthracycline and taxane containing regimen (i.e. third generation regimen), whereas those with low or moderate-risk disease may be treated with a taxane-containing regimen without an anthracycline (i.e. second generation regimen). All patients with ER- and/or PR-positive disease should always receive at least a 5-year course of endocrine therapy, usually initiated after chemotherapy is completed if given. Patients with HER2-positive disease should also always receive trastuzumab in combination with chemotherapy. Although data for adjuvant pertuzumab is currently lacking, it is recommended by National Comprehensive Cancer Center Network guidelines as a component of adjuvant therapy [107] for high-risk HER2-positive breast cancer based on improved survival when used in metastatic HER2-postive breast cancer [108], and improved pathologic complete response when used in locally advanced breast cancer [109]. On the other hand, other expert panels do not recommend use of adjuvant pertuzumab until results of the APHINITY trial (NCT01358877) become available [110], an adjuvant trial designed to determine whether adding pertuzumab to adjuvant trastuzumab-chemotherapy regimen improves clinical outcomes.

\section{Conclusions}

Localized and regionally advanced breast cancer is a potentially curative disease with local therapy alone, and adjuvant systemic chemotherapy, endocrine therapy, and anti-HER2 directed therapy substantially reduce the risk of distant recurrence and breast cancer mortality. Acute reversible effects associated with chemotherapy include alopecia, nausea, vomiting, fatigue, and myelosuppression, whereas long-term potentially irreversible effects include cardiomyopathy, acute leukemia, and neuropathy [111]. The choice of chemotherapy regimen may be individualized based upon disease-specific factors such as the underlying risk of recurrence and the projected relative and absolute benefits from chemotherapy, as well as patient-specific factors such as age, comorbidities, and risk tolerance. Decision aids may be helpful in allowing patients and caregivers to make more informed decisions about the potential benefits of adjuvant chemotherapy, and multiparameter gene expression assays may allow more accurate estimates of the potential benefits of such therapy. The TAILORx, MINDACT, RxPONDER, and OPTIMA

Table 4 Commonly recommended adjuvant chemotherapy regimens

\begin{tabular}{|c|c|c|c|}
\hline $\begin{array}{l}\text { Recurrence risk } \\
\text { category and definition }\end{array}$ & Recommended regimens: ER-positive, HER2-negative & $\begin{array}{l}\text { Recommended regimens: ER/PR- } \\
\text { negative, HER2-negative }\end{array}$ & $\begin{array}{l}\text { Recommended } \\
\text { regimens: HER2-positive }\end{array}$ \\
\hline \multicolumn{4}{|l|}{ Very low risk } \\
\hline - Node-Neg, T1a & No chemotherapy & No chemotherapy & No chemotherapy \\
\hline \multicolumn{4}{|l|}{ Low risk } \\
\hline - Node-Neg, T1b & $\begin{array}{l}\text { Consider second generation chemotherapy regimen if } \\
\text { RS is high }\end{array}$ & $\begin{array}{l}\text { Consider second generation } \\
\text { chemotherapy regimen }\end{array}$ & $\begin{array}{l}\text { Consider weekly } \\
\text { paclitaxel }+\mathrm{H}\end{array}$ \\
\hline - Node-Neg, T1c, & $\begin{array}{l}\text { Second generation chemotherapy regimen if } \mathrm{RS} \text { is high } \\
\text { (or consider if intermediate) }\end{array}$ & $\begin{array}{l}\text { Second generation chemotherapy } \\
\text { regimen }\end{array}$ & $\begin{array}{l}\text { Weekly paclitaxel }+\mathrm{H} \\
\text { or } \mathrm{TCH}\end{array}$ \\
\hline \multicolumn{4}{|l|}{ Moderate risk } \\
\hline - Node-Neg, T2 & $\begin{array}{l}\text { Second or third generation chemotherapy regimen if } \\
\text { RS intermediate-high }\end{array}$ & $\begin{array}{l}\text { Third generation chemotherapy } \\
\text { regimen }\end{array}$ & $\mathrm{AC}-\mathrm{T}+\mathrm{H}$ or $\mathrm{TCH}+/-\mathrm{P}$ \\
\hline \multicolumn{4}{|l|}{ High risk } \\
\hline$\cdot 1+$ Pos Nodes or T3 & $\begin{array}{l}\text { Third generation chemotherapy regimen if RS intermediate- } \\
\text { high (or } 4+\text { positive nodes irrespective of RS) }\end{array}$ & $\begin{array}{l}\text { Third generation chemotherapy } \\
\text { regimen }\end{array}$ & $\mathrm{AC}-\mathrm{T}+\mathrm{H}$ or $\mathrm{TCH}+/-\mathrm{P}$ \\
\hline
\end{tabular}


trials are evaluating the incorporation of multiparameter gene expression assays into clinical decision making to tailor adjuvant treatment among patients with breast cancer. Improvements in adjuvant cytotoxic regimens have contributed to declining breast cancer mortality rates and clinical trials are underway that may serve to identify subgroups deriving the greatest benefits from such therapy.

\section{Abbreviations}

AC: Doxorubicin and cyclophosphamide; CAF: Cyclophosphamide, doxorubicin, and 5-flourouracil; CMF: Cyclophosphamide, methotrexate, and 5-fluorouracil; DAC: Docetaxel, doxorubicin, and cyclophosphamide; DC: Docetaxel and cyclophosphamide; DFS: Disease-free survival; EBCTCG: Early Breast Cancer Trialists' Collaborative Group; ER: Estrogen receptor; FASG: French Adjuvant Study Group; FDA: United States Food and Drug Administration; FEC50: 5-Fluorouracil, epirubicin, and cyclophosphamide; HER2: Human epidermal growth factor receptor 2; HR: Hazard ratio; NEAT: National Epirubicin Adjuvant Trial; NSABP: National Surgical Adjuvant Breast and Bowel Project; OS: Overall survival; PR: Progesterone receptor; RS: Recurrence score.

\section{Competing interests}

The authors declare that they have no competing interests.

\section{Authors' contributions}

$J A$ : Conception and design of the work, acquisition of relevant literature, data interpretation, manuscript writing, manuscript editing, revising critical and intellectual content, Table creation and editing, and final approval of the version to be published. DM: Conception and design of the work, data interpretation, manuscript editing, revising critical and intellectual content, and final approval of the version to be published. JS: Conception and design of the work, acquisition of relevant literature, data interpretation, manuscript writing, manuscript editing, revising critical and intellectual content, and final approval of the version to be published. Expert comments and critics regarding critical data. Final revision of the protocol. All authors read and approved the final manuscript.

\section{Authors' information}

JA: Assistant Professor Medicine, Department of Medical Oncology. Albert Einstein College of Medicine/Montefiore Medical Center. DM: Assistant Professor Medicine, Department of Medical Oncology. Albert Einstein College of Medicine/Montefiore Medical Center. JS: Professor of Medicine, Department of Medical Oncology. Professor of Obstetrics, Gynecology, and Women's Health at Albert Einstein College of Medicine/Montefiore Medical Center. Associate Director for Clinical Research at Albert Einstein Cancer Center.

Received: 29 April 2015 Accepted: 29 July 2015

Published online: 17 August 2015

\section{References}

1. Jemal A, Center MM, DeSantis C, Ward EM. Global patterns of cancer incidence and mortality rates and trends. Cancer Epidemiol Biomarkers Prev. 2010;19:1893-907.

2. Torre LA, Bray F, Siegel RL, Ferlay J, Lortet-Tieulent J, Jemal A. Global cancer statistics, 2012. CA Cancer J Clin. 2015;65:87-108.

3. Siegel RL, Miller KD, Jemal A. Cancer statistics, 2015. CA Cancer J Clin. 2015;65:5-29.

4. Howlader N, Noone AM, Krapcho M, Garshell J, Miller D, Altekruse SF, et al. (eds). SEER Cancer Statistics Review, 1975-2011, National Cancer Institute. Bethesda, MD. Based on November 2013 SEER data submission, posted to the SEER web site, April 2014. http://seer.cancer.gov/csr/1975_2011/. [Last accessed 7/28/2015.]

5. Hammond ME, Hayes DF, Dowsett M, Allred DC, Hagerty KL, Badve S, et al. American Society of Clinical Oncology/College Of American Pathologists guideline recommendations for immunohistochemical testing of estrogen and progesterone receptors in breast cancer. J Clin Oncol. 2010;28:2784-95.
6. Wolff AC, Hammond ME, Hicks DG, Dowsett M, McShane LM, Allison KH, et al. American Society of Clinical Oncology; College of American Pathologists. Recommendations for human epidermal growth factor receptor 2 testing in breast cancer: American Society of Clinical Oncology/ College of American Pathologists clinical practice guideline update. J Clin Oncol. 2013;31:3997-4013.

7. Sparano JA, Fazzari M, Kenny PA. Clinical application of gene expression profiling in breast cancer. Surg Oncol Clin N Am. 2010;19:581-606.

8. Sotiriou C, Pusztai L. Gene-expression signatures in breast cancer. N Engl J Med. 2009;360:790-800.

9. Cotlar AM, Dubose JJ, Rose DM. History of surgery for breast cancer: radical to the sublime. Curr Surg. 2003;60:329-37.

10. Fisher B, Jeong JH, Anderson S, Bryant J, Fisher ER, Wolmark N. Twenty-fiveyear follow-up of a randomized trial comparing radical mastectomy, total mastectomy, and total mastectomy followed by irradiation. N Engl J Med. 2002;347:567-75.

11. Fisher B, Anderson S, Bryant J, Margolese RG, Deutsch M, Fisher ER, et al. Twenty-year follow-up of a randomized trial comparing total mastectomy, lumpectomy, and lumpectomy plus irradiation for the treatment of invasive breast cancer. N Engl J Med. 2002;347:1233-41.

12. Early Breast Cancer Trialists' Collaborative Group. Effects of adjuvant tamoxifen and of cytotoxic therapy on mortality in early breast cancer. An overview of 61 randomized trials among 28,896 women. N Engl J Med. 1988:319:1681-92.

13. Early Breast Cancer Trialists' Collaborative Group. Tamoxifen for early breast cancer. Cochrane Database Syst Rev. 2001;1:CD000486.

14. Early Breast Cancer Trialists' Collaborative Group. Effects of chemotherapy and hormonal therapy for early breast cancer on recurrence and 15-year survival: an overview of the randomised trials. Lancet. 2005;365:1687-717.

15. Early Breast Cancer Trialists' Collaborative Group (EBCTCG), Davies C, Godwin J, Gray R, Clarke M, Cutter D, et al. Relevance of breast cancer hormone receptors and other factors to the efficacy of adjuvant tamoxifen: patientlevel meta-analysis of randomised trials. Lancet. 2011;378:771-84.

16. Early Breast Cancer Trialists' Collaborative Group (EBCTCG), Peto R, Davies C, Godwin J, Gray R, Pan HC, et al. Comparisons between different polychemotherapy regimens for early breast cancer: meta-analyses of long-term outcome among 100,000 women in 123 randomised trials. Lancet. 2012;379:432-44.

17. Sorlie T, Tibshirani R, Parker J, Hastie T, Marron JS, Nobel A, et al. Repeated observation of breast tumor subtypes in independent gene expression data sets. Proc Natl Acad Sci U S A. 2003;100:8418-23.

18. Bastien RR, Rodríguez-Lescure Á, Ebbert MT, Prat A, Munárriz B, Rowe L, et al. PAM50 breast cancer subtyping by RT-qPCR and concordance with standard clinical molecular markers. BMC Med Genomics. 2012;5:44.

19. Parker JS, Mullins M, Cheang MC, Leung S, Voduc D, Vickery T, et al. Supervised risk predictor of breast cancer based on intrinsic subtypes. J Clin Oncol. 2009;27:1160-7.

20. Fisher B, Ravdin RG, Ausman RK, Slack NH, Moore GE, Noer RJ. Surgical adjuvant chemotherapy in cancer of the breast: results of a decade of cooperative investigation. Ann Surg. 1968;168:337-56.

21. Fisher B, Carbone P, Economou SG, Frelick R, Glass A, Lerner $\mathrm{H}$, et al. 1-Phenylalanine mustard (L-PAM) in the management of primary breast cancer. A report of early findings. N Engl J Med. 1975;292:117-22.

22. Bonadonna G, Brusamolino E, Valagussa P, Rossi A, Brugnatelli L, Brambilla C, et al. Combination chemotherapy as an adjuvant treatment in operable breast cancer. N Engl J Med. 1976;294:405-10.

23. Albain KS, Barlow WE, Ravdin PM, Farrar WB, Burton GV, Ketchel SJ, et al. Breast Cancer Intergroup of North America. Adjuvant chemotherapy and timing of tamoxifen in postmenopausal patients with endocrine-responsive, node-positive breast cancer: a phase 3, open-label, randomised controlled trial. Lancet. 2009;374:2055-63.

24. Mansour EG, Gray R, Shatila AH, Osborne CK, Tormey DC, Gilchrist KW, et al. Efficacy of adjuvant chemotherapy in high-risk node-negative breast cancer. An intergroup study. N Engl J Med. 1989;320:485-90.

25. Mansour EG, Gray R, Shatila AH, Tormey DC, Cooper MR, Osborne CK, et al. Survival advantage of adjuvant chemotherapy in high-risk node-negative breast cancer: ten-year analysis-an intergroup study. J Clin Oncol. 1998;16:3486-92.

26. Fisher B, Dignam J, Wolmark N, DeCillis A, Emir B, Wickerham DL, et al. Tamoxifen and chemotherapy for lymph node-negative, estrogen receptor-positive breast cancer. J Natl Cancer Inst. 1997;89:1673-82. 
27. Abrams JS. Adjuvant therapy for breast cancer-results from the USA consensus conference. Breast Cancer. 2001;8:298-304.

28. Munoz D, Near AM, van Ravesteyn NT, Lee SJ, Schechter CB, Alagoz O, et al. Effects of screening and systemic adjuvant therapy on ER-specific US breast cancer mortality. J Natl Cancer Inst. 2014;106:11.

29. Paik S, Tang G, Shak S, Kim C, Baker J, Kim W, et al. Gene expression and benefit of chemotherapy in women with node-negative, estrogen receptor-positive breast cancer. J Clin Oncol. 2006;24:3726-34.

30. Albain KS, Barlow WE, Shak S, Hortobagyi GN, Livingston RB, Yeh IT, et al. Breast Cancer Intergroup of North America. Prognostic and predictive value of the 21-gene recurrence score assay in postmenopausal women with node-positive, oestrogen-receptor-positive breast cancer on chemotherapy: a retrospective analysis of a randomised trial. Lancet Oncol. 2010;11:55-65.

31. Harris L, Fritsche H, Mennel R, Norton L, Ravdin P, Taube S, et al. American Society of Clinical Oncology. American Society of Clinical Oncology 2007 update of recommendations for the use of tumor markers in breast cancer. J Clin Oncol. 2007:25:5287-312.

32. Controlled trial of tamoxifen as adjuvant agent in management of early breast cancer, Interim analysis at four years by Nolvadex Adjuvant Trial Organisation. Lancet. 1983;1:257-61.

33. Baum M, Brinkley DM, Dossett JA, McPherson K, Patterson JS, Rubens RD, et al. Improved survival among patients treated with adjuvant tamoxifen after mastectomy for early breast cancer. Lancet. 1983:2:450.

34. Howell A, Cuzick J, Baum M, Buzdar A, Dowsett M, Forbes JF, et al. ATAC Trialists' Group. Results of the ATAC (Arimidex, Tamoxifen, Alone or in Combination) trial after completion of 5 years' adjuvant treatment for breast cancer. Lancet. 2005;365:60-2.

35. Breast International Group 1-98 Collaborative Group, Thürlimann B, Keshaviah A, Coates AS, Mouridsen H, Mauriac L, et al. A comparison of letrozole and tamoxifen in postmenopausal women with early breast cancer. N Engl J Med. 2005;353:2747-57

36. Goss PE, Ingle JN, Martino S, Robert NJ, Muss HB, Piccart MJ, et al. A randomized trial of letrozole in postmenopausal women after five years of tamoxifen therapy for early-stage breast cancer. N Engl J Med. 2003;349:1793-802.

37. Davies C, Pan H, Godwin J, Gray R, Arriagada R, Raina V, et al. Adjuvant Tamoxifen: Longer Against Shorter (ATLAS) Collaborative Group. Long-term effects of continuing adjuvant tamoxifen to 10 years versus stopping at 5 years after diagnosis of oestrogen receptor-positive breast cancer: ATLAS, a randomised trial. Lancet. 2013;381:805-16.

38. Pagani O, Regan MM, Walley BA, Fleming GF, Colleoni M, Láng I, et al. International Breast Cancer Study Group. Adjuvant exemestane with ovarian suppression in premenopausal breast cancer. N Engl J Med. 2014:371:107-18.

39. Pagani O, Regan MM, Francis PA, TEXT and SOFT Investigators; International Breast Cancer Study Group. Exemestane with ovarian suppression in premenopausal breast cancer. N Engl J Med. 2014;371:1358-9.

40. Romond EH, Perez EA, Bryant J, Suman VJ, Geyer Jr CE, Davidson NE, et al. Trastuzumab plus adjuvant chemotherapy for operable HER2-positive breast cancer. N Engl J Med. 2005;353:1673-84

41. Joensuu $H$, Kellokumpu-Lehtinen $\mathrm{PL}$, Bono $\mathrm{P}$, Alanko T, Kataja $\mathrm{V}$, Asola $\mathrm{R}$ et al. FinHer Study Investigators. Adjuvant docetaxel or vinorelbine with or without trastuzumab for breast cancer. N Engl J Med. 2006:354:809-20.

42. Piccart-Gebhart MJ, Procter M, Leyland-Jones B, Goldhirsch A, Untch M, Smith I, et al. Herceptin Adjuvant (HERA) Trial Study Team. Trastuzumab after adjuvant chemotherapy in HER2-positive breast cancer. N Engl J Med. 2005:353:1659-72

43. Slamon D, Eiermann W, Robert N, Pienkowski T, Martin M, Press M, et al. Breast Cancer International Research Group. Adjuvant trastuzumab in HER2positive breast cancer. N Engl J Med. 2011;365:1273-83.

44. Tolaney SM, Barry WT, Dang CT, Yardley DA, Moy B, Marcom PK, et al. Adjuvant paclitaxel and trastuzumab for node-negative, HER2-positive breast cancer. N Engl J Med. 2015;372:134-41.

45. Jones SE, Collea R, Paul D, Sedlacek S, Favret AM, Gore Jr I, et al. Adjuvant docetaxel and cyclophosphamide plus trastuzumab in patients with HER2-amplified early stage breast cancer: a single-group, open-label, phase 2 study. Lancet Oncol. 2013;14:1121-8.

46. Pivot $X$, Romieu G, Debled M, Pierga JY, Kerbrat $P$, Bachelot $T$, et al. PHARE trial investigators. 6 months versus 12 months of adjuvant trastuzumab for patients with HER2-positive early breast cancer (PHARE): a randomised phase 3 trial. Lancet Oncol. 2013;14:741-8.

47. Goldhirsch A, Gelber RD, Piccart-Gebhart MJ, de Azambuja E, Procter M, Suter TM, et al. Herceptin Adjuvant (HERA) Trial Study Team. 2 years versus
1 year of adjuvant trastuzumab for HER2-positive breast cancer (HERA) an open-label, randomised controlled trial. Lancet. 2013;382:1021-8.

48. Hutchinson L. Breast cancer: ALTTO: wake-up call for setting up clinical trials. Nat Rev Clin Oncol. 2013:10:121.

49. Loprinzi CL, Ravdin PM. Decision-making for patients with resectable breast cancer: individualized decisions for and by patients and their physicians. J Natl Compr Canc Netw. 2003;1:189-96.

50. Olivotto IA, Bajdik CD, Ravdin PM, Speers $C H$, Coldman AJ, Norris BD, et al. Population-based validation of the prognostic model ADJUVANT! for early breast cancer. J Clin Oncol. 2005;23:2716-25.

51. Mook S, Schmidt MK, Rutgers EJ, van de Velde AO, Visser O, Rutgers SM, et al. Calibration and discriminatory accuracy of prognosis calculation for breast cancer with the online Adjuvant! program: a hospital-based retrospective cohort study. Lancet Oncol. 2009;10:1070-6.

52. Hortobagyi GN. Anthracyclines in the treatment of cancer. An overview Drugs. 1997;54:1-7.

53. Shockman G, Waksman SA. Rhodomycin - an antibiotic produced by a red-pigmented mutant of Streptomyces griseus. Antibiot Chemother (Northfield). 1951;1:68-75.

54. Tan C, Etcubanas E, Wollner N, Rosen G, Gilladoga A, Showel J, et al. Adriamycin - an antitumor antibiotic in the treatment of neoplastic diseases. Cancer. 1973;32:9-17.

55. Brambilla C, Valagussa P, Bonadonna G. Sequential combination chemotherapy in advanced breast cancer. Cancer Chemother Pharmacol. 1978;1:35-9.

56. Sparano JA. Use of dexrazoxane and other strategies to prevent cardiomyopathy associated with doxorubicin-taxane combinations. Semin Oncol. 1998;25:66-71.

57. Torti FM, Bristow MM, Lum BL, Carter SK, Howes AE, Aston DA, et al. Cardiotoxicity of epirubicin and doxorubicin: assessment by endomyocardial biopsy. Cancer Res. 1986;46:3722-7.

58. Italian Multicentre Breast Study with Epirubicin, Ambrosini G, Balli M, Garusi G, Demicheli R, Jirillo A, et al. Phase III randomized study of fluorouracil, epirubicin, and cyclophosphamide $v$ fluorouracil, doxorubicin, and cyclophosphamide in advanced breast cancer: an Italian multicentre trial. J Clin Oncol. 1988;6:976-82

59. Wani MC, Taylor HL, Wall ME, Coggon P, McPhail AT. Plant antitumor agents. VI. The isolation and structure of taxol, a novel antileukemic and antitumor agent from Taxus brevifolia. J Am Chem Soc. 1971:93:2325-7.

60. Schiff PB, Fant J, Horwitz SB. Promotion of microtubule assembly in vitro by taxol. Nature. 1979;277:665-7.

61. Horwitz SB. Personal recollections on the early development of taxol. J Nat Prod. 2004:67:136-8.

62. Zasadil LM, Andersen KA, Yeum D, Rocque GB, Wilke LG, Tevaarwerk AJ, et al. Cytotoxicity of paclitaxel in breast cancer is due to chromosome missegregation on multipolar spindles. Sci Transl Med. 2014;6:229ra43.

63. Weaver BA. How taxol/paclitaxel kills cancer cells. Mol Biol Cell. 2014;25:2677-81.

64. Rowinsky EK, Donehower RC. Paclitaxel (taxol). N Engl J Med. 1995;332:1004-14.

65. Ringel I, Horwitz SB. Studies with RP 56976 (taxotere): a semisynthetic analogue of taxol. J Natl Cancer Inst. 1991;83:288-91.

66. Schrijvers D, Wanders J, Dirix L, Prove A, Vonck I, van Oosterom A, et al. Coping with toxicities of docetaxel (Taxotere). Ann Oncol. 1993;4:610-1.

67. Jones SE, Erban J, Overmoyer B, Budd GT, Hutchins L, Lower E, et al. Randomized phase III study of docetaxel compared with paclitaxel in metastatic breast cancer. J Clin Oncol. 2005;23:5542-51.

68. Sledge GW, Neuberg D, Bernardo P, Ingle JN, Martino S, Rowinsky EK, et al. Phase III trial of doxorubicin, paclitaxel, and the combination of doxorubicin and paclitaxel as front-line chemotherapy for metastatic breast cancer: an intergroup trial (E1193). J Clin Oncol. 2003;21:588-92.

69. Bachegowda LS, Makower DF, Sparano JA. Taxanes: impact on breast cance therapy. Anticancer Drugs. 2014;25:512-21

70. Tancini G, Bonadonna G, Valagussa P, Marchini S, Veronesi U. Adjuvant CMF in breast cancer: comparative 5-year results of 12 versus 6 cycles. J Clin Oncol. 1983;1:2-10.

71. Bonadonna G, Moliterni A, Zambetti M, Daidone MG, Pilotti S, Gianni L, et al. 30 years' follow up of randomised studies of adjuvant CMF in operable breast cancer: cohort study. BMJ. 2005;330:217.

72. Fisher B, Redmond C, Wickerham DL, Bowman D, Schipper H, Wolmark N, et al. Doxorubicin-containing regimens for the treatment of stage II breast cancer: The National Surgical Adjuvant Breast and Bowel Project experience. J Clin Oncol. 1989;7:572-82 
73. Fisher B, Brown AM, Dimitrov NV, Poisson R, Redmond C, Margolese RG, et al. Two months of doxorubicin-cyclophosphamide with and without interval reinduction therapy compared with 6 months of cyclophosphamide, methotrexate, and fluorouracil in positive-node breast cancer patients with tamoxifen-nonresponsive tumors: results from the National Surgical Adjuvant Breast and Bowel Project B-15. J Clin Oncol. 1990;8:1483-96.

74. Fisher B, Anderson S, Tan-Chiu E, Wolmark N, Wickerham DL, Fisher ER, et al. Tamoxifen and chemotherapy for axillary node-negative, estrogen receptornegative breast cancer: findings from National Surgical Adjuvant Breast and Bowel Project B-23. J Clin Oncol. 2001;19:931-42.

75. Shulman LN, Berry DA, Cirrincione CT, Becker HP, Perez EA, O'Regan R, et al. Comparison of doxorubicin and cyclophosphamide versus single-agent paclitaxel as adjuvant therapy for breast cancer in women with 0 to 3 positive axillary nodes: CALGB 40101 (Alliance). J Clin Oncol. 2014;32:2311-7.

76. Namer $M$, Fargeot $P$, Roché $H$, Campone $M$, Kerbrat $P$, Romestaing $P$, et al. French Adjuvant Study Group. Improved disease-free survival with epirubicin-based chemoendocrine adjuvant therapy compared with tamoxifen alone in one to three node-positive, estrogen-receptor-positive, postmenopausal breast cancer patients: results of French Adjuvant Study Group 02 and 07 trials. Ann Oncol. 2006;17:65-73.

77. French Epirubicin Study Group. A prospective randomized phase III trial comparing combination chemotherapy with cyclophosphamide, fluorouracil, and either doxorubicin or epirubicin. J Clin Oncol. 1988;6:679-88.

78. French Adjuvant Study Group. Benefit of a high-dose epirubicin regimen in adjuvant chemotherapy for node-positive breast cancer patients with poor prognostic factors: 5-year follow-up results of French Adjuvant Study Group 05 randomized trial. J Clin Oncol. 2001;19:602-11.

79. Sparano JA. Doxorubicin/taxane combinations: cardiac toxicity and pharmacokinetics. Semin Oncol. 1999:26:14-9.

80. Norton L. Theoretical concepts and the emerging role of taxanes in adjuvant therapy. Oncologist. 2001;6:30-5

81. Simon R, Norton L. The Norton-Simon hypothesis: designing more effective and less toxic chemotherapeutic regimens. Nat Clin Pract Oncol. 2006;3:406-7.

82. Henderson IC, Berry DA, Demetri GD, Cirrincione CT, Goldstein LJ, Martino S, et al. Improved outcomes from adding sequential Paclitaxel but not from escalating Doxorubicin dose in an adjuvant chemotherapy regimen for patients with node-positive primary breast cancer. J Clin Oncol. 2003;21:976-83.

83. Mamounas EP, Bryant J, Lembersky B, Fehrenbacher L, Sedlacek SM, Fisher B, et al. Paclitaxel after doxorubicin plus cyclophosphamide as adjuvant chemotherapy for node-positive breast cancer: results from NSABP B-28. J Clin Oncol. 2005:23:3686-96.

84. Poole CJ, Earl HM, Hiller L, Dunn JA, Bathers S, Grieve RJ, et al. NEAT Investigators and the SCTBG. Epirubicin and cyclophosphamide, methotrexate, and fluorouracil as adjuvant therapy for early breast cancer. N Engl J Med. 2006;355:1851-62.

85. Jones S, Holmes FA, O'Shaughnessy J, Blum JL, Vukelja SJ, Mclntyre KJ, et al. Docetaxel with cyclophosphamide is associated with an overall survival benefit compared with doxorubicin and cyclophosphamide: 7-year followup of US Oncology Research Trial 9735. J Clin Oncol. 2009;27:1177-83.

86. Nabholtz JM, Mackey JR, Smylie M, Paterson A, Noël DR, Al-Tweigeri T, et al. Phase II study of docetaxel, doxorubicin, and cyclophosphamide as first-line chemotherapy for metastatic breast cancer. J Clin Oncol. 2001;19:314-21.

87. Nabholtz JM, Falkson C, Campos D, Szanto J, Martin M, Chan S, et al. Docetaxel and doxorubicin compared with doxorubicin and cyclophosphamide as first-line chemotherapy for metastatic breast cancer: results of a randomized, multicenter, phase III trial. J Clin Oncol. 2003:21:968-75.

88. Sparano JA, O'Neill A, Schaefer PL, Falkson Cl, Wood WC. Phase II trial of doxorubicin and docetaxel plus granulocyte colony-stimulating factor in metastatic breast cancer: Eastern Cooperative Oncology Group Study E1196. J Clin Oncol. 2000;18:2369-77.

89. Martin M, Pienkowski T, Mackey J, Pawlicki M, Guastalla JP, Weaver C, et al. Breast Cancer International Research Group 001 Investigators. Adjuvant docetaxel for node-positive breast cancer. N Engl J Med. 2005;352:2302-13.

90. Nabholtz JM PT, Mackey J, Pienkowski T, Pawlicki M, Guastalla JP, Vogel C, et al. Phase III trial comparing TAC (docetaxel, doxorubicin, cyclophosphamide) with FAC (5-fluorouracil, doxorubicin, cyclophosphamide) in the adjuvant treatment of node positive breast cancer (BC) patients: interim analysis of the BCIRG 001 study. Proc Am Soc Clin Oncol. 2002;21:36a.

91. Martin M, Seguí MA, Antón A, Ruiz A, Ramos M, Adrover E, et al. GEICAM 9805 Investigators. Adjuvant docetaxel for high-risk, node-negative breast cancer. N Engl J Med. 2010;363:2200-10.
92. Roche H, Fumoleau P, Spielmann M, Canon JL, Delozier T, Serin D, et al. Sequential adjuvant epirubicin-based and docetaxel chemotherapy for node-positive breast cancer patients: the FNCLCC PACS 01 Trial. J Clin Oncol. 2006;24:5664-71.

93. Coudert B, Asselain B, Campone M, Spielmann M, Machiels JP, Pénault-Llorca F, et al. UNICANCER Breast Group. Extended benefit from sequential administration of docetaxel after standard fluorouracil, epirubicin, and cyclophosphamide regimen for node-positive breast cancer: the 8-year follow-up results of the UNICANCER-PACS01 trial. Oncologist. 2012;17:900-9.

94. Ellis $P$, Barrett-Lee $P$, Johnson L, Cameron D, Wardley A, O'Reilly $S$, et al. TACT Trial Management Group; TACT Trialists. Sequential docetaxel as adjuvant chemotherapy for early breast cancer (TACT): an open-label, phase III, randomised controlled trial. Lancet. 2009;373:1681-92.

95. Martin M, Rodríguez-Lescure A, Ruiz A, Alba E, Calvo L, Ruiz-Borrego M, et al. GEICAM 9906 Study Investigators. Randomized phase 3 trial of fluorouracil, epirubicin, and cyclophosphamide alone or followed by Paclitaxel for early breast cancer. J Natl Cancer Inst. 2008;100:805-14.

96. Skipper HE. Laboratory models: some historical perspective. Cancer Treat Rep. 1986;70:3-7

97. Citron ML, Berry DA, Cirrincione C, Hudis C, Winer EP, Gradishar WJ, et al. Randomized trial of dose-dense versus conventionally scheduled and sequential versus concurrent combination chemotherapy as postoperative adjuvant treatment of node-positive primary breast cancer: first report of Intergroup Trial C9741/Cancer and Leukemia Group B Trial 9741. J Clin Oncol. 2003;21:1431-9.

98. Hudis C, Citron M, Berry D, Cirrincione C, Gradishar W, Davidson N, et al. Five year follow-up of INT C9741: dose-dense (DD) chemotherapy (CRX) is safe and effective. San Antonio, TX: San Antonio Breast Cancer Symposium; 2005.

99. Bonilla L, Ben-Aharon I, Vidal L, Gafter-Gvili A, Leibovici L, Stemmer SM. Dose-dense chemotherapy in nonmetastatic breast cancer: a systematic review and meta-analysis of randomized controlled trials. J Natl Cancer Inst. 2010;102:1845-54.

100. Sparano JA, Wang M, Martino S, Jones V, Perez EA, Saphner T, et al. Weekly paclitaxel in the adjuvant treatment of breast cancer. $\mathrm{N}$ Engl J Med. 2008;358:1663-71.

101. Sparano JA, Zhao F, Martino S, Ligibel J, Saphner T, Wolff AC, et al. Ten year update of E1199: Phase III study of doxorubicin-cyclophosphamide followed by paclitaxel or docetaxel given every 3 weeks or weekly in patients with axillary node-positive or high-risk node-negative breast cancer. San Antonio, TX: San Antonio Breast Cancer Symposium; 2014.

102. Budd GT, Barlow WE, Moore HC, Hobday TJ, Stewart JA, Isaacs C, et al. SWOG S0221: a phase III trial comparing chemotherapy schedules in highrisk early-stage breast cancer. J Clin Oncol. 2015;33:58-64.

103. Swain SM, Jeong JH, Geyer Jr CE, Costantino JP, Pajon ER, Fehrenbacher L, et al. Longer therapy, iatrogenic amenorrhea, and survival in early breast cancer. N Engl J Med. 2010;362:2053-65.

104. Sparano JA, Solin LJ. Defining the clinical utility of gene expression assays in breast cancer: the intersection of science and art in clinical decision making. J Clin Oncol. 2010;28:1625-7.

105. Sparano JA, Paik S. Development of the 21-gene assay and its application in clinical practice and clinical trials. J Clin Oncol. 2008;26:721-8.

106. Cardoso F, Piccart-Gebhart M, Van't Veer L, Rutgers E, TRANSBIG Consortium. The MINDACT trial: the first prospective clinical validation of a genomic tool. Mol Oncol. 2007;1:246-51.

107. National Comprehensive Cancer Network. www.nccn.org [Last accessed 7/28/2015\}]

108. Swain SM, Kim SB, Cortés J, Ro J, Semiglazov V, Campone M, et al. Pertuzumab, trastuzumab, and docetaxel for HER2-positive metastatic breast cancer (CLEOPATRA study): overall survival results from a randomised, double-blind, placebo-controlled, phase 3 study. Lancet Oncol. 2013;14:461-71.

109. Schneeweiss A, Chia S, Hickish T, Harvey V, Eniu A, Hegg R, et al. Pertuzumab plus trastuzumab in combination with standard neoadjuvant anthracycline-containing and anthracycline-free chemotherapy regimens in patients with HER2-positive early breast cancer: a randomized phase II cardiac safety study (TRYPHAENA). Ann Oncol. 2013;24:2278-84.

110. Coates AS, Winer EP, Goldhirsch A, Gelber RD, Gnant M, Piccart-Gebhart M et al. Panel Members. Tailoring therapies-improving the management of early breast cancer: St Gallen International Expert Consensus on the Primary Therapy of Early Breast Cancer 2015. Ann Oncol. 2015;26:1533-46.

111. Mayer EL. Early and late long-term effects of adjuvant chemotherapy. Am Soc Clin Oncol Educ Book. 2013. p. 9-14. doi:10.1200/EdBook_AM.2013.33.9. 
112. Mackey JR, Martin M, Pienkowski T, Rolski J, Guastalla JP, Sami A, et al. TRIO/BCIRG 001 investigators. Adjuvant docetaxel, doxorubicin, and cyclophosphamide in node-positive breast cancer: 10-year follow-up of the phase 3 randomised BCIRG 001 trial. Lancet Oncol. 2013;14:72-80.

113. Martin M, Ruiz A, Ruiz Borrego M, Barnadas A, González S, Calvo L, et al. Fluorouracil, doxorubicin, and cyclophosphamide (FAC) versus FAC followed by weekly paclitaxel as adjuvant therapy for high-risk, node-negative breast cancer: results from the GEICAM/2003-02 study. J Clin Oncol. 2013;31:2593-9.

\section{Submit your next manuscript to BioMed Central} and take full advantage of:

- Convenient online submission

- Thorough peer review

- No space constraints or color figure charges

- Immediate publication on acceptance

- Inclusion in PubMed, CAS, Scopus and Google Scholar

- Research which is freely available for redistribution 